\title{
Student Engagement with Online Tutorial: A Perspective on Flow Theory
}

\author{
http://dx.doi.org/10.3991/ijet.v10i1.4348 \\ P.I. Santosa \\ Universitas Gadjah Mada, Yogyakarta, Indonesia
}

\begin{abstract}
When students are dealing with online tutorial, there are challengers they must answer using any skill they have. The challenge and skill must be at the same 'height' in order for them to immerse with online tutorial activities. Several aspects will be considered as challenge and skill. One challenge under the scrutiny is the page length used to present course materials. The length of tutorial presented in an online tutorial portal varies depending on its topic. The comfort of long tutorial reading depends on how the materials being presented in an online tutorial website, whether it is presented as one long page or shorter multi pages. The comfort that the students obtain from reading an online tutorial may influence whether they decide to continue reading the material or abandon it. This paper reports the result of a study to investigate how tutorial length influences student engagement. The research method employed in this study was a laboratory experiment followed by a post experiment survey where respondents were asked to give their opinion about several statements related to the research variables. Respondents were students who were voluntarily agree to participate in this experiment; total respondents were 95 students. Six hypotheses were tested using PLS, and all of them were supported by the collected data.
\end{abstract}

Index Terms - student engagement, flow theory, page length, prior knowlesge

\section{INTRODUCTION}

The Internet has penetrated almost all aspects in human life, including education. The delivery of course materials have come under different name including online tutorial, online learning, distance learning, eLearning, and webbased tutorial by taking into account the different in their scopes. Web-based distance learning and other similar system with different terms, has been implemented using different strategies. These strategies can be characterized based on the initiative in creating the web-based distance learning, whether it was an individual effort, group effort, or institutional effort [1]. A recent study done by [2] showed that a web-based platform that runs on any device equipped with the Internet and a web browser could motivate and engage students, enhancing or even replacing more traditional teaching methodologies. This study however, did not mention what factors affecting student engagement. In different setting, [3] investigated the direct effects of online learning on distance education. Amongst other hypotheses, they hypothesized that a direct relationship existed between students' engagement in online learning and distance outcomes. Internet skill had significant effect on students' engagement. Liaw and Huang [4] showed that students were more engaged in the interaction with eLearning system when they experienced an optimal experience often named as flow [5]. The flow experience was characterized by immersive, enjoyment, and perceived control.

Recent studies that have been conducted to compare the Internet mediated course deliveries with face-to-face classroom were done by e.g. [6] and [7]. The above studies were conducted to understand which method of course delivery affected students' performance positively. The purpose of this study is to investigate factors that may influence student engagement with online tutorial. Several factors were investigated including online tutorial design, delivery and prior knowledge.

\section{LiteratURE REVIEW}

\section{A. Online Tutorial}

The Internet mediated course delivery has come under several names. Moore et al. [8] studied whether eLearning, online learning, and distance learning were the same. They compared several definition used in the previous studies. They found that those definitions were used interchangeably and inconsistently. However, the previous studies agreed to one thing, i.e. the technology for delivering the content. As with traditional classroom, there is also some sort of interaction in distance learning. Interaction in traditional setting includes student-student, instructorinstructor, and student-instructor interactions. They also have to interact with the course materials. In online setting, the interaction is extended to interaction with technology needed for online tutorial.

Online tutorial can be categorized into asynchronous computer mediated forum [9]. In this system students and teachers do not have to be present at the same time. This situation brings pros and cons between scholars and researchers. Proponents of online tutorial believe that due to more spreading usage of the Internet and its related technologies, this mode of delivering courses offers unique experience [7]. Due to the asynchronous nature of online tutorial, "students are able to work at a pace consistent with their rate of learning, have more time to reflect, to feel more in control of the learning process, and to engage in more self-directed and independent learning" [9, p. 662]. It supports flexibility in term of time in which teaching and learning takes place [6]. With the technology that could be used for delivering the course materials become widely available, more complete variations, and more affordable, providing rich learning environment using rich media is even easier than before. This situation creates better teaching-learning spaces and environments. Online tutorials are in improving students' understanding and performance [10] because online tutorials are effective, easy to use, clear, useful [11], and convenient [12]. 
PAPER

Student Engagement With OnLine Tutorial: A PERSPECTIVE ON Flow TheORY

Opponents of online tutorial believe that in certain situation, students need some sort of clue that can only be provided in a classroom setting. A study conducted by [10] stated that paralinguistic cues influenced students' in understanding course materials. Missing paralinguistic cues made the students harder to study the subject materials. Thus, students were rapidly exposed to poor pedagogy [6]. This is due to lack of direct, face-to-face interaction between instructors and students [7]. Jensen [12] also mentioned that during the course of online tutorial it was hard for students to maintain attention. As a result, students have learned less in online course [7]. As such, online tutorial may not be ideal for students who lack in self-discipline, independence, computer or technology, time management, or advanced communication; students who require more hands-on assistance were also in doubt [13].

In order to understand whether online tutorial was preferable as compared to its classroom counterpart, several studies linked the outcome of online tutorial with several variables, e.g. knowledge retention, e.g. [14] and [15], satisfaction, engagement, institutional presence, learning outcomes, and intent-to-persist [3]. Study on the effectiveness of mobile learning and student preference for mobile learning indicated that mobile devices were effective tool for providing short and basic information. When it was compared to traditional classroom, the knowledge retention in later mode was higher than that of open and distance learning [14]. On the other hand, [15] reported the opposite result. An online tutorial covering principles of diabetes care was used as a test case. Their finding suggested that online tutorial helps physicians in improving their knowledge retention. More specific finding stated that knowledge retention was higher to those who were given a posttest immediately after online tutorial as compared to those who were given longer delay before posttest. Since students' familiarity with online tutorial technologies varies, their appreciation toward different content delivery technology could be different.

Studies have also shown that online tutorial and classroom course were not significantly different in students' outcome. York [16] conducted a study using 3 modes of course delivery, i.e. traditional class, Internet-based, and a mix between the two. Surprisingly, the result showed that these three modes had no significant difference in knowledge gain and student satisfaction.

\section{B. Flow Theory}

Students who are dealing with course material presented in an tutorial need to have at least basic understanding of how to work with the online tutorial system as well as the course material. In this situation, reading the course material and at the same time navigating the system require concentration that can bring students into a psychological state known as flow. Flow refers to extremely enjoyable and optimal experiences when a person engages in certain activity with total enjoyment, concentration, and involvement [5].

Flow theory has been applied in several fields including games and marketing. Flow has also been applied or considered in education. Santosa [17] proposed a conceptual framework to apply flow theory to improve performance in a web-based course. One proposition said, "Flow experienced by students will affects their performance positively" (p 527). Davis and Wong [18] investigated stu- dents' affective perception in eLearning environment. One of the findings said that flow had positive effect on intention to use.

\section{Student Engagement}

Students are engaged with a system when they "hold their attention and they are attracted to it for intrinsic rewards" [19, p. 58]. According to [20], engagement is similar to flow. In order to attract students, thus facilitating better engagement, the system must be designed to include personalization, aesthetic, and ease of navigation. In other words, the system must be designed to please the students who are using it.

After much deliberation and conducting extensive literature review, [21] proposed an engagement model comprising point of engagement, engagement, disengagement, and reengagement. Based on this model, they defined engagement as "a quality of user experiences with technology that is characterized by challenge, aesthetic and sensory appeal, feedback, novelty, interactivity, perceived control and time, awareness, motivation, interest, and affect" (p. 23). The above attributes were grouped into process, emotional, sensory, and spatiotemporal threads of experience. This definition suggests that in order for the students to have better engagement with online tutorial, they must be provided with a fun and enjoyable system for them to play with.

A study that employed system usage to measure engagement was conducted by [18]. The result was inline with [22]. In the later study, virtual learning environment (VLE) log files from students working on certain task were analyzed to determine their engagement with VLE. The finding revealed that students from different faculties reported wide variety of engagement.

\section{Attitude Toward Online Tutorial}

Technology Acceptance Model or TAM [23], said that intention was an immediate antecedent of certain behavior. The behavior was most likely to be performed when intention was stronger. People would form an intention toward certain behavior when he had a strong attitude toward that behavior. Subsequently, attitude was positively influenced by students' perception of the technology they used in term of their perceived ease of use and perceived usefulness. These two different perceptions, yet related, can only be understood after students played or worked with certain technology. TAM has been used in great number of studies, especially those related to technology usage.

Studies related to attitude toward eLearning, especially the one related to TAM, have been conducted. The most recent study conducted by [24] stated that students' had high attitude toward eLearning. On the closer look, however, there were mixed findings in regard to gender difference. Liaw and Huang [25] showed that gender difference was obvious when it came to e-learning attitude. Male learners had more positive attitude compared to its opposite gender. This result differed from [24] that there was no significant difference in attitude toward eLearning for both male and female.

\section{E. Web Navigation}

In general, navigation is a method used to bring oneself to certain location, either in real or virtual world. In real world, people often use certain landmark to guide them into a place they want to go. In some cases, users often 
experienced some difficulties due to unfamiliarity with the location they want to visit. This unfamiliarity may cause disorientation, e.g. [20]. In order to help users finding certain places, navigation cues are often employed. In real world, navigation cues can be in the form of road signs, traffic signs, neon signs, and the like.

Huizhing [26] divided Web design element into content component and design component. Content component comprised any information that would be presented, including text, graphics, animation, and even embedded video. Design component comprised information and navigational features. Similar with real world, navigating in a Web was best helped with navigation cues in the form of next and previous buttons, navigation bars, breadcrumbs menu, links, sitemap, directories, and search facilities. The importance of navigation in a Web was apparent because students could not see all information presented. The benefit of having good navigation scheme was to reduce disorientation as well as to allow its users to be more engaged in their Web activities [20].

When engaging in a web-related activity, users must carry out multiple tasks concurrently [27]. These multiple tasks are navigational tasks, informational tasks, and task management. Navigational task comprises planning and executing routes within the information space. Informational task is a task to read and understand the presented information contents for further analysis and summary. Task management coordinates informational and navigational tasks, e.g. keeping track of digressions to incidental topics. If the task management was getting mixed up, it could end up in disorientation, e.g. [20].

\section{F. Prior Knowledge}

Prior knowledge is a combination of knowledge and skills [28]. Prior knowledge is a significant variable influencing student achievement. Because every individual is different, prior knowledge not only can enhance the learning process, but also can be used to personalize instructional support that different from task to task [29].

As prior knowledge is an important prerequisite for individual knowledge construction and learning outcome [30], neglecting it may result in difficulties in completing courses or degrees. In dealing with new information that leads to the new construction of knowledge, prior knowledge affects how the learner perceived new information, organize new information, and how easily students make connections for new information to form new knowledge [31].

\section{G. Webpage Length}

According to [32], students were most likely to "scan" the Web content rather than read from top to bottom. Thus, content designer must consider the length of online tutorial as it was considered as online tutorial complexity [34]. Web page length was also related to reliability [35].

Problems related to page length have been identified in previous studies. For example, [35] found out that varying page length significantly affected web search performance. In different setting, [36] conducted a study on how the web-based survey questionnaire affecting participation. The finding was as expected that respondents were more willing to answer and complete questionnaires when the length of questionnaires is short.

Santosa [37] conducted a study to investigate web page length preference. In this study, web content was present- ed using three different metaphors as manifestation of the web page length. The metaphors used were "paper roll" where web content was presented in one long page, "slider" that allows its students to go back and forth sequentially, and "textbook" where they are allowed to move from one page to the other freely. One of the finding showed that students did not care about the page length they used. However, another finding showed that students who were exposed with different page length resulted in different perceived benefit, attitude toward reading materials, and perceived ease of navigation.

\section{H. Perceived Benefit and Cost}

Santosa [38] conducted an analysis that during information seeking activities, students might get benefit and incurred cost related to web design elements. In this study, benefit was defined as term used to quantify the positive expected results or outputs of a proposed activity (http://goo.gl/VfNTfo). Cost was defined as an amount that has to be paid or given up in order to get something (http://www.businessdictionary.com/definition/cost.html). This benefit and cost could be tangible or intangible forms. Tangible benefit was apparent when he got the information he was looking for that could bring intangible benefit such as satisfaction. On the other hand, it might also possible that when during the course of information seeking activities he never found what he wished to get. In this case he might feel disappointed, i.e. sort of intangible cost.

Zhang and von Dran [39] proposed a two-factor model for Website design and evaluation. It comprised motivators and hygiene factors. Based on this model, [38] mapped several factors of Web design elements into perceived benefit and perceived cost. Figure 1 presents the mapping of such factors.

\section{Hypotheses Development}

Challenge and skill are seen to be important aspects that influence users in doing certain activities [5]. As the purpose of this study is to investigate student engagement with online tutorial, these two aspects are strongly considered. Following [17], this study employs skill and challenge manifested as prior knowledge and page length, respectively.

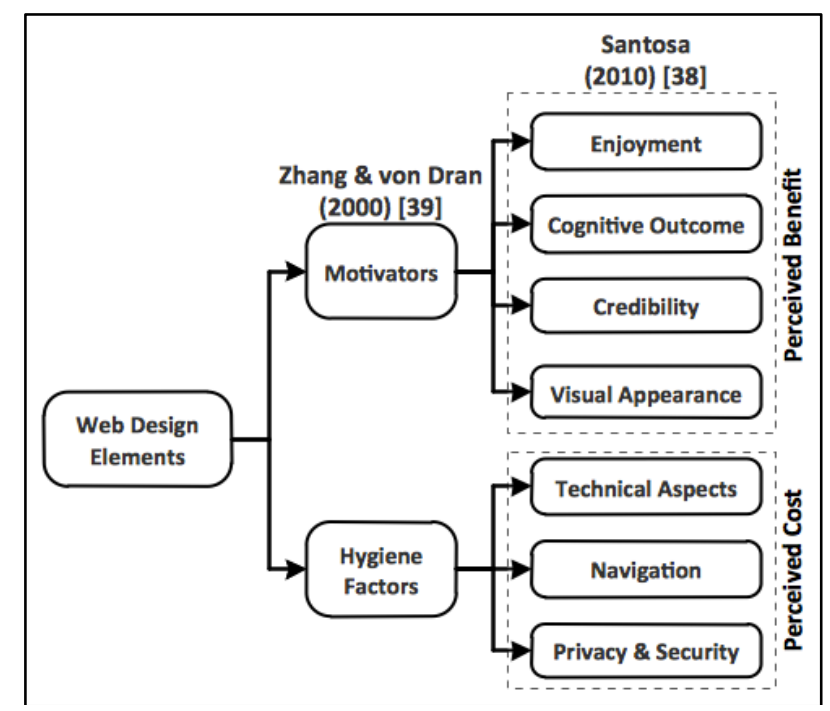

Figure 1. Mapping motivators and hygiene factors into perceived benefit and perceived cost, respectively 
As stated by [32], students prefer "scan" the interesting part of the presented readings from top to bottom sequentially. Longer reading presentation forces students to scroll up and down to find certain part of the readings. Different page length influences web search performance [35], perceived ease of use [37], and reading speed [40]. Searching for information in the information space requires certain skill in navigating oneself into the expected information. Whether the search will be easy or complex depending on the page length as well as how the information being presented as part of the information visualization. Therefore, the first hypothesis is stated:

H1: Perceived page length suitability will have positive influence on perceived ease of navigation

Hailikari [28] stated that prior knowledge comprises knowledge and skill. Skill is needed to steer oneself to certain location. With appropriate knowledge to understand the provided navigation cues, students may move around very easily. Therefore, the second hypothesis is stated:

$\mathrm{H} 2$ : Prior knowledge will have positive influence on perceived ease of navigation

Students with better navigation skill will be less likely to experience disorientation. When students feel that the navigation is easy, they will perceive that the system is easy to use. TAM postulates that perceived ease of use influences attitude positively [23]. It is argued that when students can move around easily in an online tutorial setting, they will perceive that the online tutorial is easy to use. The linearity of navigation path influences navigation task difficulty [41]. If the students feel that the navigation task is difficult they probably will abandon the task in hand, and create negative attitude toward that task. Although an appropriate Web design is independent to the topics, however, the page length influences web reliability [34]. Broken links or "page not found" will influence the web reliability. Therefore, the third hypothesis is stated:

$\mathrm{H} 3$ : Perceived ease of navigation will have positive influence on student attitude toward online tutorial

Davis and Wong [18] employed engagement as a measure of system usage. In TAM, system usage was influenced by intention, which in turn influenced by attitude. A recent study of attitude toward eLearning conducted by [24] confirmed [18] finding. As such, the forth hypothesis is stated:

H4: Student attitude will have positive influence on student engagement with online tutorial reading activity

When doing certain Web activities, students will gain certain benefit and at the same time will incur certain cost. Enjoyment, positive outcomes as well as nice visual appearance will promote usage. On the other hand, broken links, slow Internet speed, and confusing navigation will prevent students from using online tutorial due to uncertainty to what they will gain. Therefore the last two hypotheses are stated:

H5: Perceived benefit the student gains during his online tutorial activity will have positive impact on his engagement

H6: Perceived cost the student incurred during his online tutorial activity will have negative impact on his engagement

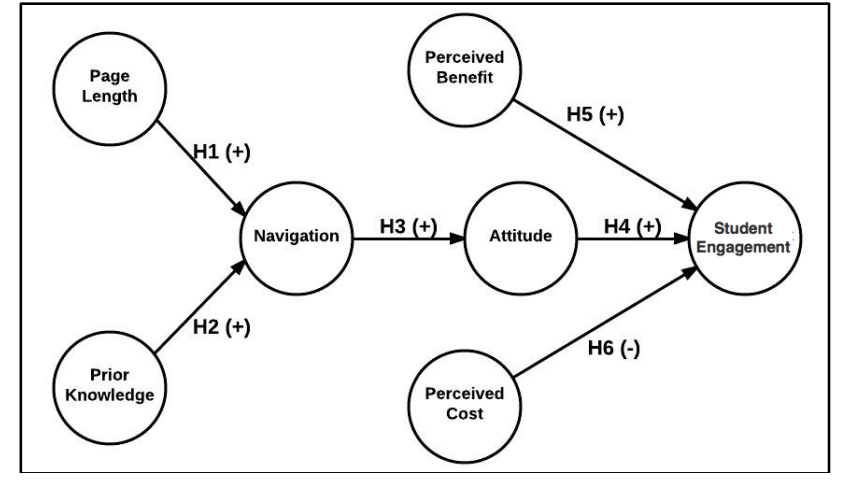

Figure 2. The research model.

TABLE I.

CONSTRUCTS OPERATIONALIZATION

\begin{tabular}{|l|l|}
\hline \multicolumn{1}{|c|}{ Construct Name } & \multicolumn{1}{|c|}{ Definition } \\
\hline $\begin{array}{l}\text { Page length suitability } \\
\text { (PL) }\end{array}$ & $\begin{array}{l}\text { The degree to which the students perceived } \\
\text { that the page length used to present the } \\
\text { course materials is suitable for them }\end{array}$ \\
\hline Prior knowledge (PK) & $\begin{array}{l}\text { Knowledge that is possessed by student } \\
\text { related to the presented course materials }\end{array}$ \\
\hline $\begin{array}{l}\text { Perceived ease of naviga- } \\
\text { tion (PN) }\end{array}$ & $\begin{array}{l}\text { The degree to which the students perceive } \\
\text { that the navigation used to move around the } \\
\text { presented course materials is easy or straight } \\
\text { forward }\end{array}$ \\
\hline $\begin{array}{l}\text { Attitude toward online } \\
\text { tutorial (AT) }\end{array}$ & $\begin{array}{l}\text { The degree of favor or disfavor toward } \\
\text { online tutorial }\end{array}$ \\
\hline Perceived benefit (PB) & $\begin{array}{l}\text { The degree to which the students perceive } \\
\text { that reading course materials results in } \\
\text { additional knowledge }\end{array}$ \\
\hline $\begin{array}{l}\text { Perceived cost } \\
\text { (PC) }\end{array}$ & $\begin{array}{l}\text { The degree to which the students perceive } \\
\text { that reading course materials incurred } \\
\text { certain cost }\end{array}$ \\
\hline $\begin{array}{l}\text { Student engagement } \\
\text { (UE) }\end{array}$ & $\begin{array}{l}\text { The degree to which the students engage in } \\
\text { online tutorial }\end{array}$ \\
\hline
\end{tabular}

Figure 2 shows all of the above hypotheses drawn in the research model. The operationalization of all constructs is presented in Table I.

\section{RESEARCH METHOD}

\section{A. Experiment Subjects}

This study employed a laboratory experiment followed by a post experiment survey. Subjects of the experiment were undergraduate students who were voluntarily participated in this study after a call for participation email was sent to them. In total, there were 95 students participating in this experiment.

Subjects were divided into two groups. Both groups were given the same course material. However, the course material was presented using different metaphor for different group, i.e. paper roll and textbook [37]. Each group was admitted to the laboratory within different time slots.

\section{B. The Task and Survey Instrument}

The task given to the subjects was simple. They were asked to read a tutorial material about data structure. The material was written in Indonesian language. It comprised two chapters about two sorting methods, i.e. Bubble Sort and Quick Sort.

After finish reading the material, subjects were asked to answer 5 simple questions related the material they just 
read. Upon finishing this simple exercise, subjects were asked to complete a survey comprising 28 questions. The purpose of this survey was to obtain respondents' perception about their experience with online tutorial presented in different page length. Table II presents survey questionnaires that will be completed by the experiment subjects after they have finished the experiment. The original questionnaires were presented in Indonesian language, and Table II presents the English version of the questionnaires. There are seven latent variables in total. Each latent variable comprises four indicators. These indicators were measured using 5-point Likert scale, where " 1 " means "strongly disagree" and " 5 " means "strongly agree".

\section{DATA ANALYSIS}

Data analysis and hypotheses testing were conducted using Student Version of SmartPLS 3 [42]. Data analysis using PLS requires two-step analysis, i.e. measurement model and structural model.

\section{A. Measurement Model}

Measurement model analysis was used to analyze the adequacy of measurement reliability and validity. One measure of reliability was item reliability or loading value of certain indicator to its latent variable. According to [43], the minimum loading value suitable for subsequent analysis was 0.707 . The first iteration indicated that two indicators of PL (PL1 and PL2) and two indicators of UE (UE1 and UE2) had loading value less than 0.707 . Therefore, these four indicators were excluded for further analysis. By deleting these indicators, item reliability, composite reliability, loadings and cross loadings were all appropriate for further analysis (due to limited number of pages, loadings and cross loadings were not presented here. Interested parties shall email the author to get list of loadings and cross loading). Furthermore, from Table III it can be observed that discriminant validity is appropriate. As such the measurement model is satisfactory that structural model can be analyzed.

\section{B. Structural Model}

Structural model shows the relationship among latent variables in the research model, thus it directly determines whether certain hypothesis was supported by the collected data. Table IV presents the result of structural model analysis in term of path coefficients according to the given hypotheses. By using $\alpha=0.05$, it can be observed that all hypotheses are supported by the collected data. Figure 3 shows the result of the hypotheses test in term of their respective path coefficient.

Figure 3 also shows the coefficient of determination of the model. It can be observed that $\mathrm{R}^{2}$ for student engagement (UE) is 0.40 . This means that about $40 \%$ of the variance of student engagement was due the variables in the model.

\section{DISCUSSION}

Student engagement has been the focus of this article. Six hypotheses were proposed and all of them were supported by the collected data. Four exogenous were used to test the hypotheses, two of them were seen as the web design manifested as benefit and cost of students dealing with online tutorial. The other two, prior knowledge and perceived page suitability, can be seen from different perspective.
TABEL II

SURVEY QUESTIONNAIRES

\begin{tabular}{|c|c|}
\hline \multirow{4}{*}{$\begin{array}{l}\text { Page length suitabil- } \\
\text { ity }\end{array}$} & The page length is good \\
\hline & The page length fits my need \\
\hline & The page length is as I expected \\
\hline & The page length is appropriate \\
\hline \multirow{4}{*}{ Prior knowledge } & I familiar with the presented topics \\
\hline & I know this topic before \\
\hline & I have heard about this topic before \\
\hline & I have read this topic before \\
\hline \multirow{4}{*}{$\begin{array}{l}\text { Perceived ease of } \\
\text { navigation }\end{array}$} & The navigation is easy \\
\hline & The navigation is simple \\
\hline & The navigation is straightforward \\
\hline & The navigation is fun \\
\hline \multirow{4}{*}{$\begin{array}{l}\text { Attitude toward } \\
\text { online tutorial }\end{array}$} & Using online tutorial is positive \\
\hline & Using online tutorial is important \\
\hline & Using online tutorial is good \\
\hline & Using online tutorial is an activity I like to do \\
\hline \multirow{4}{*}{ Perceived benefit } & $\begin{array}{l}\text { The reading material expand my experience } \\
\text { about the presented topic }\end{array}$ \\
\hline & $\begin{array}{l}\text { The reading material expand my knowledge } \\
\text { about the presented topic }\end{array}$ \\
\hline & $\begin{array}{l}\text { The reading material expand my understanding } \\
\text { about the presented topic }\end{array}$ \\
\hline & $\begin{array}{l}\text { The reading material influence positively my } \\
\text { motivation to learn the presented topic }\end{array}$ \\
\hline \multirow{4}{*}{ Perceived cost } & Reading the material is only wasting my time \\
\hline & Reading the material makes me confused \\
\hline & Reading the material increases by cognitive load \\
\hline & Reading the material makes me dizzy \\
\hline \multirow{4}{*}{ Student engagement } & I feel that the reading is essential \\
\hline & I feel that the reading is significant \\
\hline & I feel that the reading is needed \\
\hline & I feel that the reading is important \\
\hline
\end{tabular}

TABLE III.

DISCRIMINANT VALIDITY

\begin{tabular}{|c|c|c|c|c|c|c|c|}
\hline & AT & PB & PC & UI & PN & PL & PK \\
\hline AT & 0.80 & & & & & & \\
\hline PB & 0.14 & 0.90 & & & & & \\
\hline PC & -.13 & -.01 & 0.84 & & & & \\
\hline UI & 0.38 & 0.46 & -.34 & 0.92 & & & \\
\hline EN & 0.50 & 0.02 & 0.05 & 0.24 & 0.78 & & \\
\hline PL & 0.25 & 0.07 & 0.23 & 0.20 & 0.34 & 0.89 & \\
\hline PK & 0.24 & 0.11 & 0.06 & 0.7 & 0.40 & 0.28 & 0.76 \\
\hline
\end{tabular}

TABLE IV

PATH COEFFICIENTS

\begin{tabular}{|l|c|c|c|}
\hline \multicolumn{1}{|c|}{ Path } & $\begin{array}{c}\text { Path Coefficient } \\
(\boldsymbol{\beta})\end{array}$ & $\begin{array}{c}\text { t value } \\
(\mathbf{p} \text { value) }\end{array}$ & Decision \\
\hline $\mathrm{H} 1: \mathrm{PL} \rightarrow \mathrm{EN}$ & 0.25 & $\begin{array}{c}\mathrm{t}=2.60 \\
\mathrm{p}=0.010\end{array}$ & Supported \\
\hline $\mathrm{H} 2: \mathrm{PK} \rightarrow \mathrm{EN}$ & 0.34 & $\begin{array}{c}\mathrm{t}=3.73 \\
\mathrm{p}=0.000\end{array}$ & Supported \\
\hline $\mathrm{H} 3: \mathrm{EN} \rightarrow \mathrm{AT}$ & 0.50 & $\begin{array}{c}\mathrm{t}=6.29 \\
\mathrm{p}=0.000\end{array}$ & Supported \\
\hline $\mathrm{H} 4: \mathrm{AT} \rightarrow \mathrm{UE}$ & 0.28 & $\begin{array}{c}\mathrm{t}=2.74 \\
\mathrm{p}=0.006\end{array}$ & Supported \\
\hline $\mathrm{H} 5: \mathrm{PB} \rightarrow \mathrm{UE}$ & 0.41 & $\begin{array}{c}\mathrm{t}=4.78 \\
\mathrm{p}=0.000\end{array}$ & Supported \\
\hline $\mathrm{H} 6: \mathrm{PC} \rightarrow \mathrm{UE}$ & -0.30 & $\begin{array}{c}\mathrm{t}=3.84 \\
\mathrm{p}=0.000\end{array}$ & Supported \\
\hline
\end{tabular}


PAPER

Student Engagement with OnLine Tutorial: A PERsPective on Flow Theory

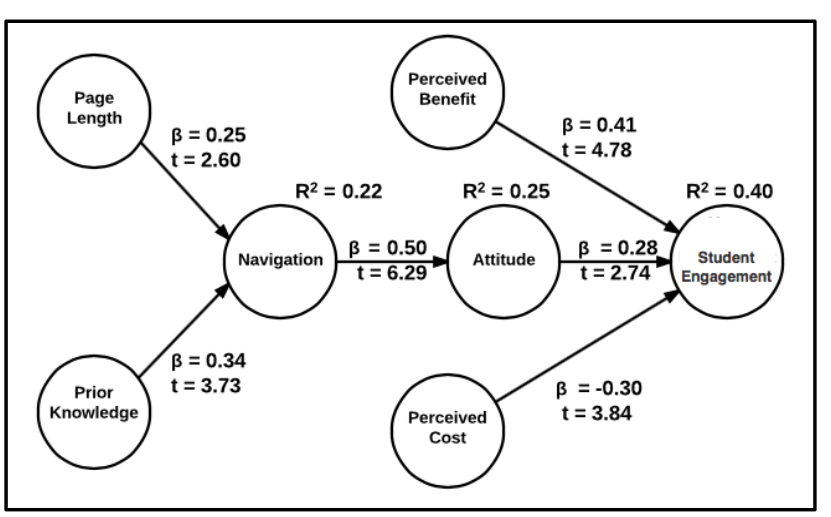

Figure 3. Hypotheses test result.

From the flow point of view, prior knowledge is considered as the manifestation of skill that the students possess to conduct certain activity [17]. On the other side, perceived page suitability is assumed as the challenge toward online tutorial. It is a challenge, because according to [33] page length has certain complexity that may influence reading speed [40], and ease of navigation. Thus, these two will be combined to perform certain activity within online tutorial, i.e. navigating through online tutorial materials. If these two antecedents of flow were matched, students were in control of their online tutorial activity [5].

From information search activity, as stated by [30], prior knowledge was important to understand the domain of the presented materials. Students' familiarity with the course materials would influence their informational task. If the course materials caught students' interest, most likely they would continue reading those materials. On the other hand, page length created a navigational task challenge. The page length used to present the course material often forces students to scroll up/down or 'flip' pages backward/forward [32]. The challenge is that students have to stay focus on certain materials while they may be exposed with abundance of information. Otherwise, disorientation is lurking [20].

Six hypotheses were proposed. Using significant level of $0.05(\alpha=0.05)$, it can be observed from Table IV that all hypotheses were supported by the data. Hypothesis 1 stated that 'perceived page length suitability would have positive influence on perceived ease of navigation'. Table III indicates that path coefficient between perceived page length suitability and perceived ease of use is $\beta=0.25(\mathrm{t}=$ $2.60, p=0.010)$. This study was not specifically investigates whether students prefer certain web page length as investigated by [37]. It was based on their perception whether the page length they were exposed to was suitable to them. However, it was stated that different page length related to different perceived of ease of navigation. If page length design were considered as part of visual design, the visual design would influence how the navigation should be designed. As such, there is positive relationship between page length and perceived ease of use. Implicitly this current study supports the above finding that page length suitability influences perceived ease of navigation.

Hypothesis 2 stated that 'prior knowledge will have positive influence on perceived ease of navigation'. Table IV indicates that path coefficient between prior knowledge and perceived ease of use is $\beta=0.34(\mathrm{t}=3.73, \mathrm{p}=0.000)$. Prior knowledge is a combination of knowledge and skill
[28]. Related to online tutorial and proposed by [17], students' prior knowledge comprises any knowledge related to the presented course materials and general web experience or web experience related to certain web design. To students who posse certain prior knowledge related to certain web, [44] stated that they had more complete mental model compared to the rest. With more complete mental model, students are able to relate online tutorial, in term of its design, better. As such, the positive relationship between prior knowledge and perceived ease of use was as expected.

It was proposed by [17] that prior knowledge relates to skill, whilst perceived page length relates to challenge. When these two are at the same pace, students will gain perceived control of online tutorial. This can be observed from the easiness of students navigating the online tutorial media.

Hypothesis 3 saw the relationship between perceived ease of navigation with attitude toward online tutorial. Table IV indicates that the path coefficient between the former and the latter is $\beta=0.50(\mathrm{t}=6.29, \mathrm{p}=0.000)$. Perceived ease of navigation can be part of 'bigger' term known as perceived ease of use [23]. There are lots of studies claiming that perceived ease of use influences attitude toward online tutorial [24]. This current study also supports [24], i.e. perceived ease of navigation influences attitude toward online tutorial positively.

Usage behavior is often studied under different terms, e.g. engagement [18] or acceptance [24]. Based on [18], this study also employed engagement as a measure of usage behavior. According to [21], engagement is characterized by interest and affect. This interest came from positive attitude after students having been exposed to online tutorial, especially in term of its technology and course materials. As shown in Table IV, Hypothesis 4 that relates attitude toward online tutorial with student engagement is supported by the collected data. This evidence indicates that path coefficient between attitude and engagement is $\beta=0.28(\mathrm{t}=2.74, \mathrm{p}=0.006)$. This finding supports [22].

Technologically, online tutorial can be implemented using several mediums, e.g. website, thus it is called webbased tutorial. In a general sense, as a web-based system, online tutorial design must follow certain guidelines in order to determine its elements. Zhang and Dran [39] classified web elements into motivators and hygiene factors. Motivators are those elements that can motivate students to stay focus with online tutorial, whilst hygiene factors are those elements that make the online tutorial proceeds normally.

In order to pinpoint certain course materials, students are often forced to conduct search activity. Search activity is bounded by cost-benefit analysis [38]. In this sense, search activity is not always resulting in the intended materials. On the other hand, students may find course materials that are not on their focus previously. This simple example provides the reason why search is bounded to cost-benefit analysis. Subsequently, Figure 1 shows the mapping of motivators and hygiene factors into benefit and cost, respectively. Students who stay focus in their online tutorial activities hold their attention to get the intrinsic rewards [19]. Figure 1 shows that intrinsic rewards could be in the form of enjoyment and cognitive outcome. Attention to online tutorial can be maintained by 
providing students with nice course material presentations, interesting interface, as well as visually appealing presentations. All of these are summarized as motivators. In other word, perceived benefit influences engagement positively. As hypothesized in Hypothesis 5, Table IV gives evidence about this relationship, i.e. path coefficient between perceived benefit and engagement is $\beta=0.41(\mathrm{t}=$ $4.78, \mathrm{p}=0.000)$.

Using the above argument, when problems exist in the design of online tutorial in regards to its content and its delivery, students' attention might fade away that they abandon the online tutorial. As such, based on Hypothesis 6 , when perceived cost is great, the students will abandon their online tutorial activity. This relationship is evidence from the fact that the path coefficient between perceived cost and engagement is $\beta=-0.30(t=3.84, p=0.000)$.

\section{CONCLUSION AND FUTURE WORKS}

This study proposed a model to measure student engagement with online tutorial. It is not specifically pinpointing certain aspect, like course material or media design, but they were treated as a whole. In this model, usage behavior was manifested as engagement. Flow theory was considered to influence the model where challenge and skill were manifested as perceived page length and prior knowledge. In term of online tutorial design, it was manifested as perceived benefit and perceived cost.

There were six hypotheses tested, and all of them were supported by the collected data. Specifically, prior knowledge and perceived page length suitability influenced perceived ease of navigation, respectively; perceived ease of navigation influenced attitude positively; subsequently attitude influenced engagement positively. In term of how technology influences engagement, the design of online tutorial was manifested as perceived benefit and perceived cost, and as hypothesized, perceived benefit and perceived cost influenced engagement positively and negatively, respectively.

This study concludes that in term of technology used in online tutorial, student engagement is influenced by several factors related to online tutorial design as well as how students perceive whether online tutorial providing them with net benefit, i.e. the difference between perceived benefit and perceived cost. Referring back to flow theory, this study also provides evidence that flow could happen in form of student engagement with online forum.

This current study has two limitations. The first limitation is that this study did not consider gender difference that might be interesting to certain people. As previously stated, there were conflicting findings regarding gender difference. For example, [24] found that there is no gender difference when it comes to attitude toward online tutorial. On the other hand [25] mentioned that gender difference was obvious. In order to gain better understanding whether any gender difference in regards to their engagement, the future study should consider this aspect. The second limitation is the fact that this study did not consider any learning style difference. It is interesting to see whether different learning styles result in different level of engagements. Thus, the future works should address at least one of the above two limitations.

\section{REFERENCES}

[1] S. Reisman, R.G. Dear, and D. Edge, "Evolution of Web-based Distance Learning Strategies", The International Journal of Educational Management, 2001, Vo. 15(5), pp. 245-251. http://dx.doi.org/10.1108/09513540110396913

[2] C-M. Mork, "Benefits of Using Online Student Response Systems in Javanese EFL Classrooms", The Jalt Call Journal, 2014, Vol. 10(2), pp. 127-137.

[3] N. Shin and J.K.Y. Chan, "Direct and Indirect Effects of Online Learning on Distance Education", British Journal of Educational Technology, 2004, Vol. 35(3), pp. 275-288. http://dx.doi.org/10.1111/j.0007-1013.2004.00389.x

[4] S-S. Liaw and H-M. Huang, "An Investigation of User Attitudes Toward Search Engines as an Information Retrieval Tool", Computers in Human Behavior, 2003, Vol. 19(6), pp. 751-765. http://dx.doi.org/10.1016/S0747-5632(03)00009-8

[5] M. Csikszentmihalyi, Flow: The Psychology of Optimal Experience, New York: Harper and Row, 1990.

[6] J. Nash, "A Tale of Two Forums: One Professor's Path to Improve Learning Through a Common Online Teaching Tool", Journal of Research om Leadership Education, December 2011, Vol. 6(5), pp. 181-194.

[7] K. Bergstrand and S. V. Savage, "The Chalkboard Versus the Avatar: Comparing the Effectiveness of Online and Inclass Courses", Teaching Sociology, 2013, Vol. 41(3), pp. 294-306. http://dx.doi.org/10.1177/0092055X13479949

[8] J.L. Moore, C. Dickson-Deane, and K. Galyen, "e-Learning, Online Learning, and Distance Learning Environments: Are They The Same?", The Internet and Higher Education, 2011, Vol. 14, pp. 129-135. http://dx.doi.org/10.1016/j.iheduc.2010.10.001

[9] D.L. Thompson, "Beyond the Classroom Walls: Teachers' and Students' Perspectives on How Online Learning Can Meet the Needs of Gifted Students", Journal of Advanced Academics, Summer 2010, Vol. 21(4), pp. 662-712. http://dx.doi.org/10.1177/ 1932202X1002100405

[10] L. Price, J.T.E. Richardson, and A. Jelfs, "Face-to-face versus online tutoring support in distance education", Studies in Higher Education, February 2007, Vol. 32(1), pp. 1-20. http://dx.doi.org/10.1080/03075070601004366

[11] C.L. Aberson, D.E. Berger, M.R. Healy, and V.L. Romero (2003), "Evaluation of an Interactive Tutorial for Teaching Hypothesis Testing Concepts", Teaching of Psychology, 2003, Vol. 30(1), pp. 75-78. http://dx.doi.org/10.1207/S15328023TOP3001_12

[12] S.A. Jensen (2011), "In-Class Versus Online Video Lectures: Similar Learning Outcomes, but a Preference for In-Class", Teaching of Psychology, Vol. 38(4), pp. 298-302. http://dx.doi.org/10.1177/0098628311421336

[13] C.S. Li and I. Beverly, "An Overview of Online Education: Attractiveness, Benefits, Challenges, Concerns and Recommendations", College Student Journal, 2008, Vol. 42, pp. 449-458.

[14] B.I. Fozdar and L.S. Kumar, "Mobile Learning and Student Retention", International Review of Research in Open and Distance Learning, June 2007, Vol. 8(2), pp. 1-18.

[15] D.S. Bell, C.E. Harless, J.K. Higa, E.L. Bjork, R.A. Bjork, M. Bazargan, and C.M. Mangione, "Knowledge Retention after an Online Tutorial: A Randomized Educational Experiment among Resident Physicians", Journal of General Internal Medicine, August 2008, Vol. 23(8), pp. 1164-1171. http://dx.doi.org/10.1007/ s11606-008-0604-2

[16] R. O. York, "Comparing Three Modes of Instruction in a Graduate Social Work Program", Journal of Social Work Education, 2008, Vol. 44, pp. 157-172. http://dx.doi.org/10.5175/JSWE.2008. 200700031

[17] P.I. Santosa, “Applying Flow Theory and Technology Acceptance Model to Improve Student Performance in a Web-based Course: A Conceptual Framework", Proceedings of The Second International Conference on Multimedia and Information \& Communication Technologies in Education, December 2003, pp. 524-529. 
[18] R. Davis and D. Wong, "Conceptualizing and Measuring Optimal Experience of the eLearning Environment", Decision Sciences Journal of Innovative Education, 2007, Vol. 5(1), pp. 97-126. http://dx.doi.org/10.1111/j.1540-4609.2007.00129.x

[19] R. Jacques, J. Preece, and J.T. Carey, "Engagement as Design Concept for Hypermedia", Canadian Journal of Educational Communications, Spring 1995, pp. 49-59.

[20] Jane Webster and Jaspreet S. Ahuja, "Enhancing the Design of Web Navigation Systems: The Influence of User Disorientation on Engagement and Performance", MIS Quarterly, September 2006, Vol. 30(3), pp. 661-678.

[21] B.H.L. O'Brien and E.G. Toms, "What is User Engagement? A Conceptual Framework for Defining User Engagement with Technology", Journal of the American Society for Information Science \& Technology, 2008, Vol. 59(6), pp. 928-955. http://dx.doi.org/10.1002/asi.20801

[22] J. Urwin, "Engagement with Virtual Learning Environments: A Case Study Across Faculties", Blended Learning in Practice, January 2011, pp. 8-12.

[23] F.D. Davis, "Perceived Usefulness, Perceived Ease of Use, and User Acceptance of Information Technology," MIS Quarterly, 1989, Vol. 13(2), pp. 319-340. http://dx.doi.org/10.2307/249008

[24] D. Kar, B. Saha, and B.C. Mondal, "Attitude of University Students towards E-learning in West Bengal," American Journal of Education Research, August 2014, Vol. 2(8), pp. 669-673. http://dx.doi.org/10.12691/education-2-8-16

[25] S-S. Liaw and H-M. Huang, "A study of investigating learners attitudes toward e-learning", The Fifth International Conference on Distance Learning and Education-IPCSIT, 2011, Vol. 12, pp. 28-32.

[26] E.K.R.E. Huizingh, "The content and design of Web sites: an empirical study," Information \& Management, 2000, Vol. 37(3), pp. 123-134. http://dx.doi.org/10.1016/S0378-7206(99)00044-0

[27] H. Kim and S.C. Hirtle, "Spatial metaphors and disorientation in hypertext browsing," Behavior and Information Technology, 1995, Vol. 14(5), pp. 239-250. http://dx.doi.org/10.1080/01449299 508914637

[28] T. Hailikari,"Assessing University Students' Prior Knowledge, Implication for Theory and Practice", University of Helsinki Department of Education Research Report 227, 2009.

[29] E. Krupka and N. Tishby, "Incorporating Prior Knowledge on Features into Learning", Proceedings of the Eleventh International Conference on Artificial Intelligence and Statistics, March 21-24, 2007, Vol. 2, pp. 227.234.

[30] B. Ertl and H. Mandl, "Effects of Individual Prior Knowledge on Collaborative Knowledge Construction and Individual Learning Outcomes", Proceedings of the Conference Knowledge Construction in E-learning Context: CSCL, ODL, ICT and SNA in Education, September 2008, Vol. 398.

[31] M. Svinicki, "What They Don't Know Can Hurt Them: The Role of Prior Knowledge in Learning", Essays on Teaching Excellence Toward the Best in the Academy, 1993-94, Vol. 5(4).

[32] D. A. Cook and D. M. Dupras, "A Practical Guide To Developing Effective Web-based Learning", Journal of General Internal Medicine, 2004, Vol. 19, pp. 698-707 http://dx.doi.org/10.1111/j.15251497.2004.30029.x

[33] G. Geissler, G. Zinkhan, R. T. Watson, "Web Home Page Complexity and Communication Effectiveness", Journal of the Association of Information Systems, April 2001, Vol. 2(2), pp. 1-48.

[34] C. Eickhoff, P. Serdyukov, and Arjen P. de Vries, "Webpage Classification on Child Suitability", Proceedings of the $19^{\text {th }}$ Con- ference on Information and Knowledge Management, October 2010.

[35] D. Cai, S. Yu, J-R. Wen, W-Y. Ma, "Block-based Web Search", SIGIR'04 Proceedings of The 27th Annual International ACM SIGIR Conference on Research and Development in Information Retrieval, July 25-29, 2004, pp. 456-463.

[36] M. Galesic and M. Bosnjak, "Effects of Questionnaire Length on Participation and Indicators of Response Quality in A Web Survey", Public Opinion Quarterly, Summer 2009, Vol. 73(2), pp. 349-360 http://dx.doi.org/10.1093/poq/nfp031

[37] P.I. Santosa, "User Preference of Web Page Length", International Journal of Research and Review in Computer Science, March 2011, Vol. 2(1), pp. 180-185.

[38] P.I. Santosa, "Cost and Benefit of Information Search Using Two Different Strategies", Telkomnika, December 2010, Vol. 8(3), pp. 195-206.

[39] P. Zhang and G.M. von Dran, "Satisfiers and Dissatisfiers: A Two-Factor Model for Website Design and Evaluation", Journal of the American Society for Information Science, 2000, Vol. 51(14), pp. 1253-1268. http://dx.doi.org/10.1002/10974571(2000)9999:9999<::AID-ASI1039>3.0.CO;2-O

[40] Mary C. Dyson and Mark Haselgrove, "The influence of reading speed and line length on the effectiveness of reading from screen", International Journal of Human-Computer Studies, 2001, Vol. 54, 585-612. http://dx.doi.org/10.1006/ijhc.2001.0458

[41] Jacek Gwizdka and Ian Spence, "What Can Searching Behavior Tell Us About the Difficulty of Information Tasks? A Study of Web Navigation", Proceedings of the 69th Annual Meeting of the American Society for Information Science and Technology (ASIS\&T), 2006, Vol. 43, pp. 1-13.

[42] C.M. Ringle, S. Wende, and J-M. Becker, SmartPLS 3, 2014. SmartPLS 3. Hamburg: SmartPLS. Retrieved from http://www. smartpls.com.

[43] C. Fornell, G.J. Tellis, and G.M. Zinkhan, "Validity Assessment: A Structural Equations Approach Using Partial Least Squares," An Assessment of Marketing Thought and Practice, Proceedings of American Marketing Association Educator's Conference, 1982, Series No. 48, pp. 405-409.

[44] D.A. Norman, The Design of Everyday Things, 2002, Basic Book, New York.

\section{AUTHORS}

Paulus Insap Santosa, Ph.D. is currently Assistant Professor in the Department of Electrical Engineering \& Information Technology, Faculty of Engineering, Universitas Gadjah Mada, Jalan Grafika No. 2, Yogyakarta, Indonesia (email: insap@ugm.ac.id). He obtained his undergraduate degree from the department he is with now. He earned his master from University of Colorado, Boulder. He received the Ph.D. degree from the Department of Information Systems, School of Computing, National University of Singapore. He is currently Vice Chair of Indonesia ACM SIGCHI Chapter established on May, 2014. His research interest includes Human Computer Interaction, User Experience and Usability, Web Design, eLearning, and ICT in Education.

Submitted 19 December 2014. Published as resubmitted by the authors 21 February 2015. 